\title{
Evaluation of Strength of End Structures in Intermediate Rolling Stock of a Train During Train Collision Accidents
}

\author{
Yasushi UJITA \\ Vehicle and Bogie Parts Strength Laboratory, Vehicle Structure Technology Division \\ This evaluation deals with the structural design standard for rolling stock body struc- \\ tures from the viewpoint of the crashworthiness. Current Japanese Industrial Standard \\ JIS E 7106 Code, which defines the minimum static loading conditions required to provide \\ structural integrity of carbody structures for their normal operation, does not explicitly take \\ the crashworthiness into account. Here, one of the detailed FE models for the end structures \\ of EMUs, designed in accordance with the JIS E 7106 standard, was taken as an example, \\ and numerical analysis was carried out under several irregular loading conditions such as \\ the collision of end structures of intermediate rolling stock in a rake, caused by overriding \\ or train set buckling occurring during train collision accidents. The results of the numerical \\ analyses have shown some points that need to be resolved in terms of the strength of the super \\ structures as well as draw gears around coupling devices.
}

Keywords: rolling stock, carbody, structural strength, crashworthiness

\section{Introduction}

The basic functions with which the carbody structure of passenger rolling stock should be equipped are considered to include the provision of safety, integrity, comfort, economy, and sustainability.

There is no doubt that safety and integrity are the most important functions with which the carbody shells should be equipped in order to keep passengers and crew safe during both usual operation and train accidents. When a train is involved in a serious accident, rolling stock is often derailed and may experience significant deviation from the track. In such accidents, the condition and behavior of couplers between the carriages of the train are likely causes of train set buckling and the overriding of coupled rolling stock, which can easily lead to severe damage of the intermediate end structures and major deformation of the survival space in the carbody for passengers on board. It is therefore important to design the structural strength of the coupling ends of intermediate carbodies with due consideration for countermeasures aimed at avoiding such severe deformation by train set buckling and overriding of rolling stock. It is also important to design the couplers and draft gears so as to avoid the buckling and overriding as much as possible.

In this evaluation, the Japanese design standard for passenger rolling stock was reviewed from the viewpoint of crashworthiness, for the intermediate rolling stock of a train in particular.

\section{Structural standard for rolling stock carbodies}

The strength of a car body structure is defined by its integrity under static loads, according to the general requirements for the design of rolling stock for the Japanese railroads, such as the JIS E 7106 standard [1]. JIS E 7106 indicates different cases of loading of body structures, such
Table 1 Design values for the coupler load defined by the JIS E 7106 standard

\begin{tabular}{c|c|c}
\hline Loading direction & $\begin{array}{c}\text { Shinkansen high speed EMUs, } \\
\text { loco-hauled passenger rolling stock } \\
{[\mathrm{kN}]}\end{array}$ & $\begin{array}{c}\text { EMUs and DMUs } \\
{[\mathrm{kN}]}\end{array}$ \\
\hline Compression load & 980 & $345 \sim 490$ \\
\hline Tensile load & 490 & 345 \\
\hline
\end{tabular}

as the vertical load distributed on the floor structure, the longitudinal load at couplers, the torsion moment at bolsters supported by bogies, as well as fatigue strength for the cyclic pressure load applied to body structures of carriages during operation on high speed lines with tunnels. The vertical load represents the weight of an overcrowded car full of passengers. The loading conditions specified in JIS E 7106 have been established in accordance with experiences of Japanese railroad industry over more than 100 years, mainly focusing on ordinary operating conditions of rolling stock [2][3].

With regard to the longitudinal load, the strength of carbody structures is defined by the coupler loads according to JIS E 7106. This means that there is no description of the loads applied to such super structures as the roof, end posts, collision posts, corner posts, and the end panel in JIS E 7106, in contrast with the European standards, i.e. EN12663 or American standards, i.e. APTA SS-C\&S-034-99 and corresponding FRA requirements. In addition, JIS E 7106 does not explicitly provide a quantitative definition in terms of crashworthiness. Table 1 shows the design values for the coupler load specified in JIS E 7106. This coupler load is based on the static loading condition at the structural design stage of rolling stock. 


\section{Evaluation of carbody strength for intermediate coaches}

The Japanese rolling stock has a system with an automatic coupler without side buffers. According to the JIS E 7106 standard, the required coupler load is defined as the maximum load that does not cause a permanent deformation in carbody structures. JIS E 7106 does not provide the breakdown load for couplers and draft gears, which could be an important parameter affecting the phenomena of overriding, whereas the draft gears are fitted between two center sills of the under-floor structure using metal rivets, which are expected to be broken during the accident event in order to avoid overriding and train set buckling [4]. Figure 1 shows the typical under-floor structure of end carbody shells.

Despite the lack of quantitative definition concerning the crashworthiness in the current Japanese design standard, crash behavior for one of several types of typical suburban EMUs, designed according to the conventional Japanese standard, was estimated under the typical loading condition expected at the severe train accidents by using detailed numerical simulation.

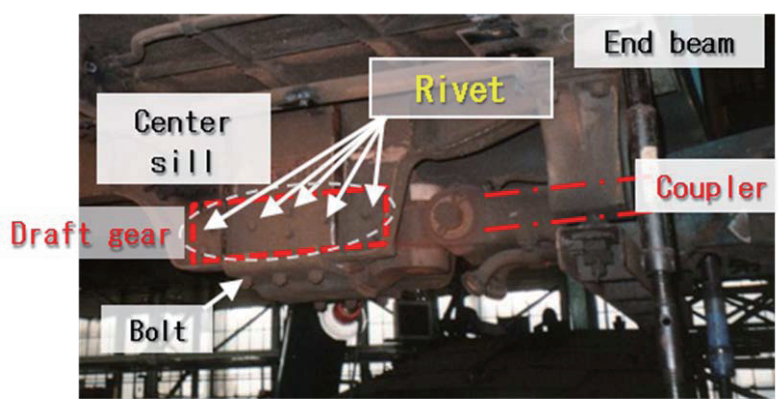

Fig. 1 Typical under-floor structure of end carbody shells

\subsection{Numerical simulation}

Most of the recently built EMUs for commuter and suburban services on Japanese railroads have stainless steel carbody structures. Therefore, lightweight carbody constructions made from austenite stainless steel, i.e. the AISI 301L series that are commonly used for a large number of commuter and suburban EMUs in Japan, have been dealt with as the main subject of this project. Figure 2 shows the typical stainless steel body structure for EMUs and Table 2 indicates the materials mainly used for stainless steel body structures.

A numerical model was constructed by providing an FE mesh that was $15 \mathrm{~mm}$ in size for the intermediate end structure of one type of suburban EMUs. Shell elements were mainly used for this model. The welded joints were included in the model and the characteristic of rupture of each joint was taken into account numerically. The test results obtained through a series of static tensile tests for small specimens determined the numerical properties of the materials. The constraints for the FE model are shown in Fig. 3. The body bolster beam was simply supported and the vertical displacement of $\mathrm{FE}$ nodes representing this beam was fixed as zero. The nodes at the "cutting edge" of the central side of the body structure were completely

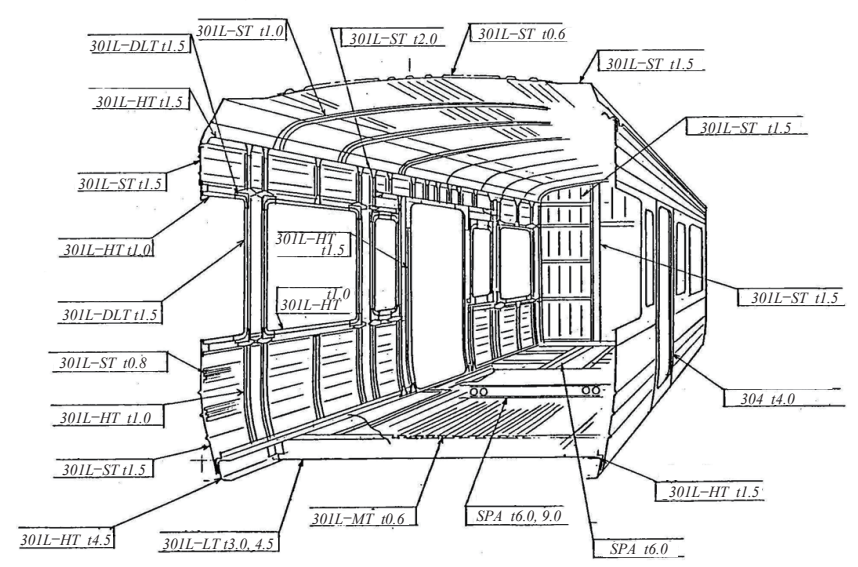

Fig. 2 Typical stainless steel body structure for EMUs

Table 2 Materials used for stainless steel body structures

\begin{tabular}{c|c}
\hline Japanese Industrial Standard & Corresponding international standard \\
\hline JIS G4305/SUS301L & AISI 301L, UNS S30103 \\
\hline JIS G3125/SPA & ASTM A242/Tyl \\
\hline
\end{tabular}

fixed. An explicit FE code "PAMCRASH" was used for this analysis. Validation for this FE model was carried out by means of comparison with the empirical results of the fullscale static compression test [5]. The loading conditions for the FE analysis are shown in Fig. 4, as well as in Table 3. These loading conditions are arranged based on the current design standard and accident scenario for the intermediate coaches of trains.

The loading conditions of case 1 for compression and case 2 for tension are equivalent to coupler loading conditions specified in the current JIS E 7106. The loading conditions of case 3 and case 5 are focused on the strength of the end beam and the side sill. For case 4 and case 6 , the loading points are situated on the super structure beside the under-floor structure. These cases represent the typical loading conditions in an overriding accident between two coupled coaches of a train. Case 7 is used for the evaluation of the strength with regard to the corner area of the roof, side structure, and end structure.

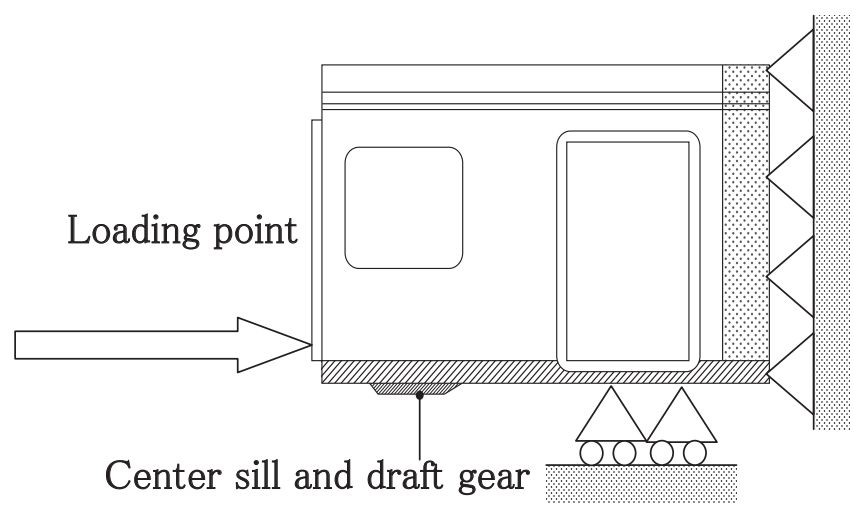

Fig. 3 General view of FE model 
Table 3 Loading conditions for the FE mesh

\begin{tabular}{c|c|c|c}
\hline Case & Loading condition & Loaded parts & Height of loading point \\
\hline 1 & $\begin{array}{c}\text { Compression load for } \\
\text { draft gear }\end{array}$ & Center sill & Center of coupler \\
\hline 3 & $\begin{array}{c}\text { Tensile load for } \\
\text { draft gear }\end{array}$ & Center sill & Center of coupler \\
\hline 4 & $\begin{array}{c}\text { End beam center } \\
\text { Lower edge of gangway }\end{array}$ & End posts at a gangway & Upper surface of under-floor \\
& Corner area of under- & structure \\
\hline 5 & End beam and side beam & Upper surface of under-floor \\
\hline
\end{tabular}
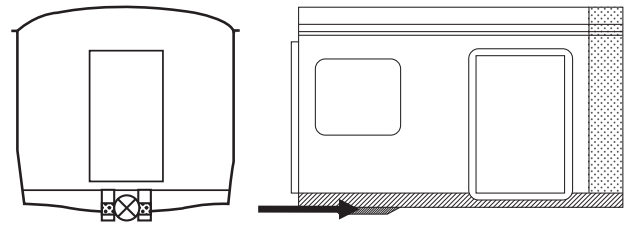

(a) Case 1: Compression load for draft gear

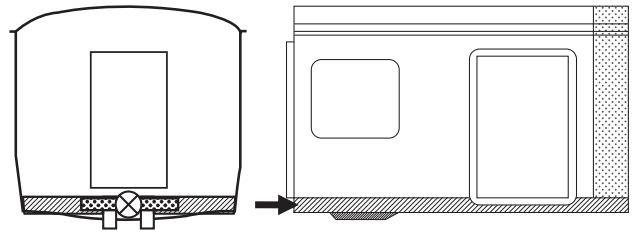

(c) Case 3: End beam center

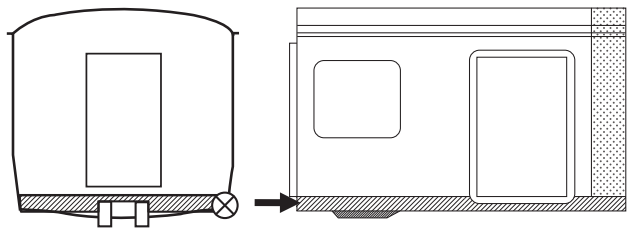

(e) Case 5: Corner area of under-floor structure

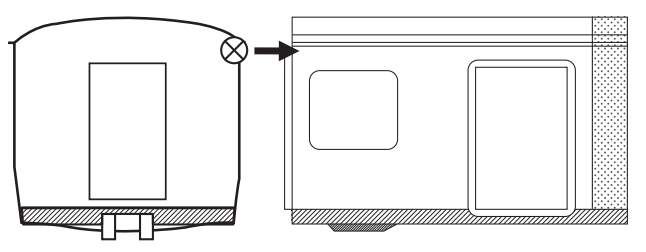

(g) Case 7: Corner if roof, side structure and panel
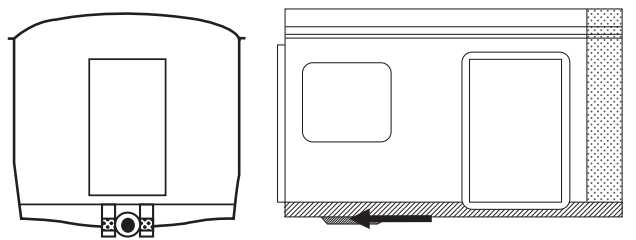

(b) Case 2: Tensile load for draft gear

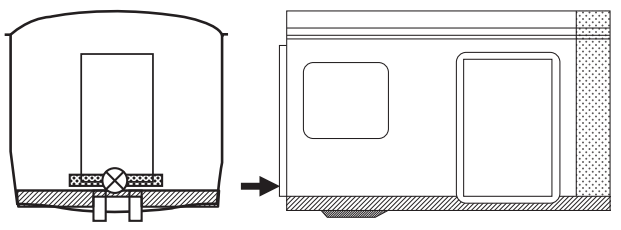

(d) Case 4: Lower edge of gangway

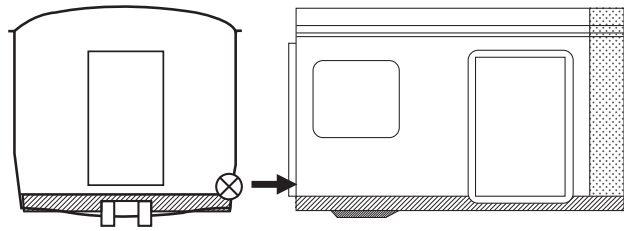

(f) Case 6: Corner post over the end beam

Fig. 4 Loading conditions for the FE analysis

\subsection{Numerical results}

The deformed FE models obtained using the calculations are shown in Fig. 5 and the relationship between the compression load and deformation is also shown in Fig. 5.

For each case, the macroscopic yield point of the carbody structure was defined as the initial inflection point of the load and deformation curve that was caused by the 
Table 4 Yield load and maximum load for each loading condition

\begin{tabular}{c|c|c|c}
\hline Case & Loading condition & $\begin{array}{c}\text { Approximate } \\
\text { yield load [kN] }\end{array}$ & $\begin{array}{c}\text { Approximate } \\
\text { maximum load [kN] }\end{array}$ \\
\hline 1 & Compression load for draft gear & 1000 & 1500 \\
\hline 2 & Tensile load for draft gear & 1000 & 3000 \\
\hline 3 & End beam center & 300 & 4500 \\
\hline 4 & Lower edge of gangway & 80 & 650 \\
\hline 5 & Corner area of under-floor structure & 600 & 190 \\
\hline 6 & Corner post over the end beam & 15 & 110 \\
\hline 7 & Corner of roof, side structure, and & 20 & \\
\hline
\end{tabular}

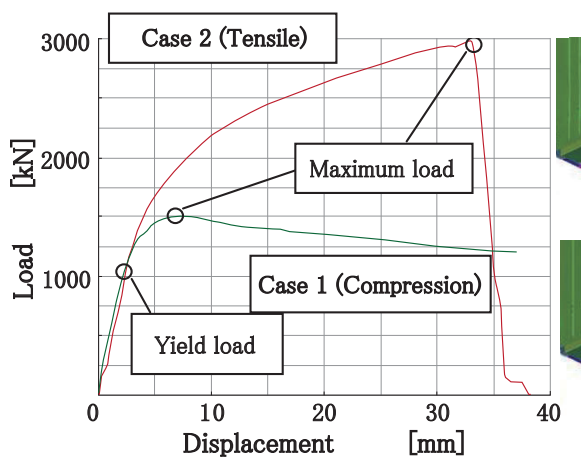

(a) Case 1 and 2: Load for draft gear
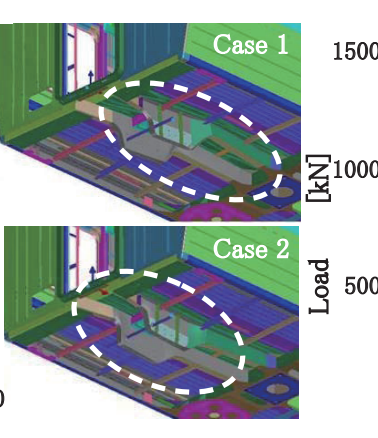

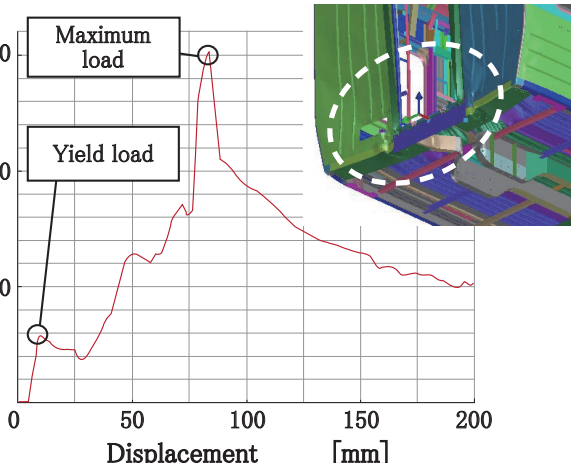

(b) Case 3: End beam center

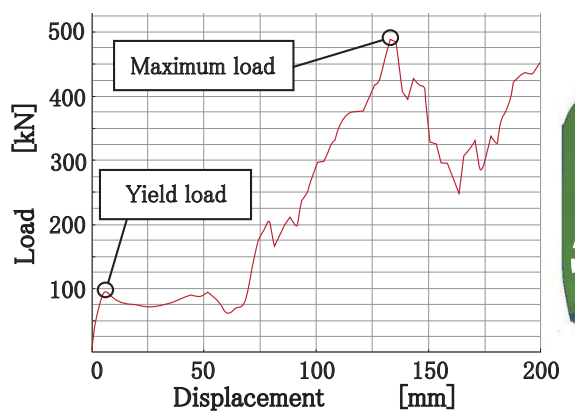

(c) Case 4: Lower edge of gangway
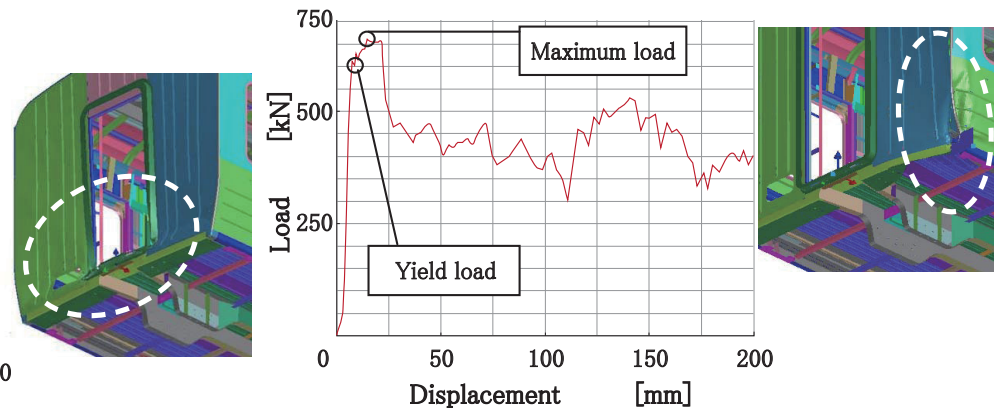

(d) Case 5: Corner area of under-floor structure

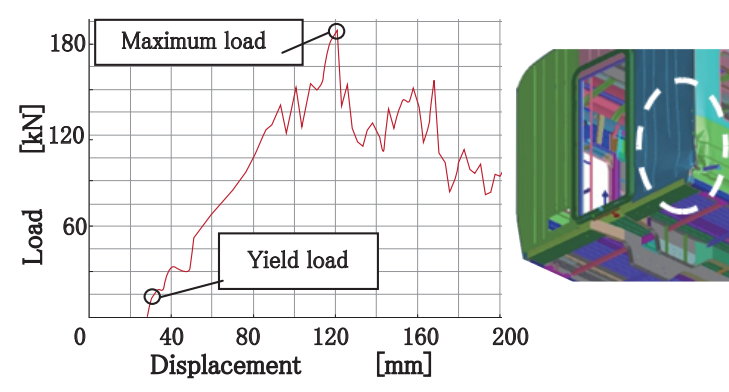

(e) Case 6: Corner post over the end beam

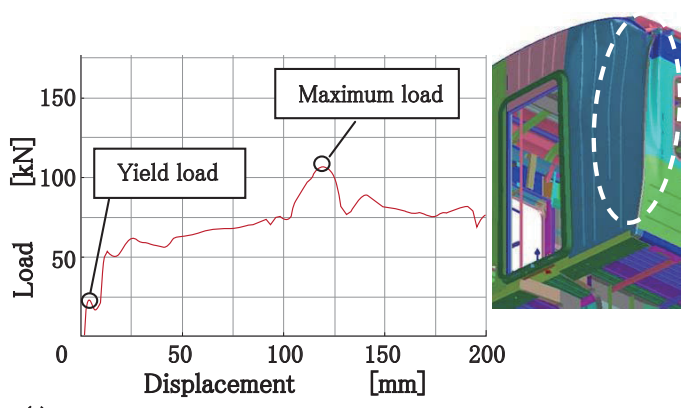

(f) Case 7: Corner of roof, side structure and end panel

Fig. 5 Numerical results for each loading condition 
transition of structural behavior from elastic deformation to nonlinear plastic deformation. The yield load and the maximum load for each case are shown in Table 4.

Using the numerical simulation, the yield load for the coupler and the draft gear at center sills in the direction of both compression and tension is estimated as approximately $1000 \mathrm{kN}$, which is two times the design value for compression and three times the design value for tension.

The deformation load of the loading cases for the end beam was estimated to be approx. 400 to $600 \mathrm{kN}$. When the loading point is situated on the super structure of carbody shells but not on the under-floor structure, the deformation load exhibits a relatively small value compared with that found in other cases.

\section{Evaluation of crushing behavior of carbody struc- tures}

The numerical calculation provides the estimated basic structural integrity against the extraordinary loading condition for intermediate end structures. Considering the schematic scenario of assumed train collision accidents such as train set buckling and overriding behavior (as shown in Fig. 6), it is essential that the coupler and the draft gear should be broken at the deformation load lower than that of the under-floor structure of the carbody shell in order to avoid train set buckling and overriding as much as possible. If train set buckling with large deviation of rail carriages from the proper rail track due to derailment (as shown in Fig. 7) is considered, then the loading cases for corner posts and the roof area would occur. These are equivalent to the numerical simulation for cases 5 to 7 as shown in Fig. 5. Unless the coupler breaks with a tensile load of less than the total reaction force of deformation for the corner posts and roof area, the super structure of carbodies would be seriously damaged and the survival space for passengers on board would be reduced. It is also important to stiffen and fasten the super structures, especially the joint section around the under-floor structure, side structure, and roof panel in order to secure such survival

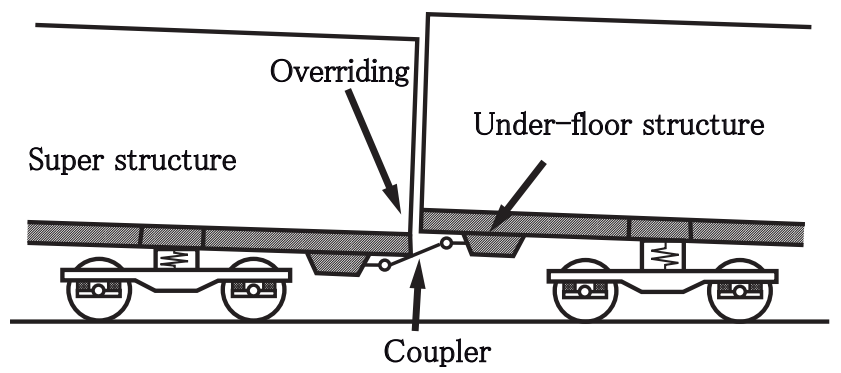

Fig. 6 Overriding phenomena of coupled rolling stock

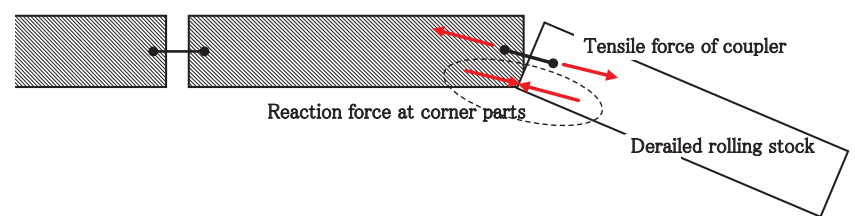

Fig. 7 Train set buckling with large deviation of rolling stock spaces for passengers even if train set buckling and overriding occur.

\section{Discussion}

\subsection{Strength of couplers and draft gears}

As described above, the breakdown load for couplers and draft-gears is considered to be an important parameter affecting the phenomena of overriding. Although the metal rivets connecting the draft gears and center sills of the under-floor structure were previously thought to be broken during accident events in order to avoid overriding and train set buckling, the actual breaking load during the rapture of metal rivets is not known in quantitative terms. In this study, the detailed numerical model for the end carbody structure, including proper rapture of spot-welding on the stainless steel body structure, was constructed and used to estimate the structural integrity of end carbody structures. However, the rapture of metal rivets has not yet been taken into account. The deformation behavior of the coupler, draft gears, and center sills including metal rivets must be clarified through empirical tests, in order to build accurate numerical models.

\subsection{Recommendation on the crashworthy end body structures}

JIS E 7106 currently defines the minimum static loading conditions required to ensure structural integrity of carbody structures for their normal operation, but does not explicitly take the crashworthiness into account. Although the longitudinal strength of carbody structures is defined by the coupler loads according to the JIS E 7106, this conventional standard does not define the breakdown load for couplers and draft gears. There is no description of the load cases to be applied to such super structures as the roof, end posts, collision posts, corner posts, and the end panel. It is necessary to improve the crashworthiness of intermediate end carbody structures by clarifying the proper strength of the coupler and draft gear, center sills, and the end beam, as well as the super structure of carbodies including side structures and roof panels.

\section{Conclusion}

The structural design standard for rolling stock body structures was evaluated from the viewpoint of crashworthiness. Using one of the detailed FE models for the end structures of EMUs, designed in accordance with the JIS E 7106 standard, numerical analysis was carried out under several irregular loading conditions such as the collision of end structures of intermediate rolling stock of a train, caused by overriding or train set buckling occurring during train collision accidents. The numerical analyses results have shown the following points:

(1) The yield load for the coupler and the draft gear at center sills in the direction of both compression and tension was evaluated to be approximately $1000 \mathrm{kN}$, which is estimated as two times the design value for 
compression and three times the design value for tension.

(2) When the loading point is situated on the super structure of carbody shells but not on the under-floor structure, the deformation load exhibits a relatively small value compared with that found in other cases.

(3) The coupler and the draft gear should be broken at a lower deformation load than that of the under-floor structure of the carbody shell in order to avoid the train set buckling and overriding.

(4) It is necessary to clarify the deformation behavior of coupler, draft-gears, and center sills including metal rivets using the empirical tests, in order to build accurate numerical models.

\section{References}

[1] Japanese Industrial Standard E 7106 "Rolling Stock - General requirements of carbody structures for passenger car, " Japanese Standards Association, 2006 (In Japanese).

[2] Osaka, K., Kyakukasha kougaku, Japan Society of Me- chanical Engineers, Vol. 1, pp. 82, 1948 (In Japanese).

[3] Railway Technical Research Institute, Kousoku tetsudou no kenkyuu, Ken-yuu-sha, pp. 306, 1967 (In Japanese).

[4] Osaka, K., Kyakukasha kougaku. Japan Society of Mechanical Engineers, Vol. 2, pp. 630, 1950 (In Japanese).

[5] Okino, T. and Ujita, Y., "Light Weight Stainless Steel Carbody Structure and Crash Behavior of Train Collision Accidents," presented at the 6th Inter-national Symposium Passive Safety of Rail Vehicles, Berlin, Germany, December 4-5, 2006, pp. 115-133, IFV-Bahntechnik.

\section{Authors}

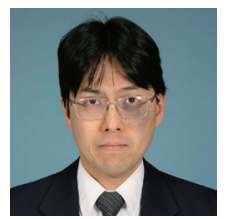

Yasushi UJITA

Laboratory Head, Vehicle and Bogie Parts Strength Laboratory, Vehicle Structure Technology Division Research Areas: Structural Integrity, Carbody Structure, Crashworthiness 